CrossMark $\leftarrow$ click for updates

Cite this: Org. Biomol. Chem., 2016, 14, 8039

Received 1st July 2016,

Accepted 1st August 2016

DOI: $10.1039 / c 6 o b 01419 d$

www.rsc.org/obc

\section{Synthesis of substituted benzooxaborinin-1-ols via palladium-catalysed cyclisation of alkenyl- and alkynyl-boronic acids $\uparrow$}

\author{
Laure Benhamou, ${ }^{\star}$ Daniel W. Walker, Dejan-Krešimir Bučar, Abil E. Aliev and \\ Tom D. Sheppard*
}

Two new palladium-catalysed reactions have been developed for the synthesis of stable 4-substituted benzooxaborinin-1-ols. A palladium-catalysed cyclisation of ortho-alkenylbenzene boronic acids can be used to access 4-chlorobenzooxaborinin-1-ols via a Wacker-type oxidation and chlorination. Alternatively, orthoalkynylbenzene boronic acids undergo a palladium-catalysed oxyallylation reaction to provide 4-allylbenzooxaborinin-1-ols.

Organoboron compounds are widely used in organic chemistry, most notably in metal-catalysed reactions. ${ }^{1}$ More recently, however, organoboron compounds have found applications in a diverse array of areas including direct amidation reactions, ${ }^{2}$ novel materials, ${ }^{3}$ and as sensors for chemical biology. ${ }^{1,4}$ To date, however, there are relatively few applications of organoboron compounds in medicinal chemistry. ${ }^{1}$ There are nevertheless an increasing number of "boron therapeutics" beginning to emerge, ${ }^{5}$ including peptidomimetics such as Bortezomib (Fig. 1) and cluster structures for application in neutron capture therapy. ${ }^{6}$ More recently, boron-containing
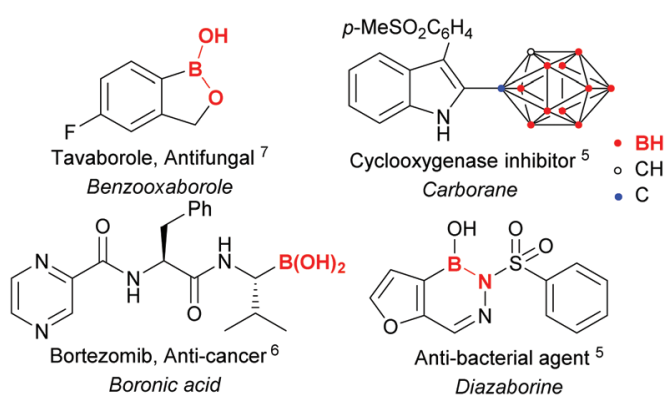

Fig. 1 Boron-containing compounds in medicinal chemistry.

Department of Chemistry, University College London, Christopher Ingold Laboratories, 20 Gordon St, London, WC1H OAJ, UK. E-mail: l.benhamou@ucl.ac.uk, tom.sheppard@ucl.ac.uk

$\dagger$ Electronic supplementary information (ESI) available: Full experimental procedures and ${ }^{1} \mathrm{H},{ }^{13} \mathrm{C}$ and X-ray crystallographic data. CCDC 1479176 . For ESI and crystallographic data in CIF or other electronic format see DOI: 10.1039/ c6ob01419d heterocycles have attracted considerable synthetic interest, ${ }^{7}$ with benzooxaboroles such as Tavaborole proving to be potentially interesting scaffolds for a range of medicinal chemistry applications. $^{5,8}$ In this paper, we describe novel synthetic approaches to 4-substituted benzooxaborinin-1-ols, a novel class of boron-oxygen heterocycles, which has potential applications as a new heterocyclic framework for medicinal chemistry or materials science. Whilst benzooxaborinin-1-ols have appeared in scattered reports over the past 50 years, ${ }^{9}$ little attention has been devoted to the development of new synthetic methods for accessing substituted derivatives. The related 9-Bora-10-oxa-phenanthrene ring system, containing an additional fused benzene ring, has attracted considerably more attention ${ }^{10}$ due to its application as a building block in the synthesis of $o$-phenylenes. ${ }^{11}$

Our group has a long-standing interest in organoboron chemistry and we have reported an effective method for the gold-catalysed synthesis of 3-substituted benzooxaborinin-1ols from $o$-alkynylbenzene boronic acids (Scheme 1a). ${ }^{12}$ Unfortunately, these heterocycles showed relatively low stability due to the highly electron-rich $\mathrm{C}-4$ position, ${ }^{12,13}$ limiting their potential application as heterocyclic scaffolds. In order to address this issue, we envisioned that the introduction of a substituent at the C-4 position should increase the stability of the ring system. In this paper, we present two new approaches to substituted benzooxaborinin-1-ols: (1) palladium-catalysed Wacker-type cyclisation of $o$-alkenylbenzene boronic acids ${ }^{14}$ (Scheme 1b); and (2) palladium-catalysed oxyallylation of $o$-alkynylbenzene boronic acids (Scheme 1c). In the first case (Scheme 1b), we envisaged a process similar to the Wacker oxidation. Palladium(II) catalysts are well known to activate carbon-carbon double bonds, and have been applied extensively to the oxidation of alkenes. ${ }^{15}$ Pd-catalysed cyclisation of an $o$-alkenylbenzene boronic acid should occur via formation of an alkylpalladium intermediate which will undergo $\beta-\mathrm{H}$ elimination to afford the heterocycle. For the second strategy we envisaged that $\operatorname{Pd}(\mathrm{II})$-catalysed cyclisation of an alkynylboronic acid (Scheme 1c) would give an alkenylpalladium(II) intermediate. $^{16}$ This vinyl-palladium intermediate can 
Previous work ${ }^{12}$

(a)<smiles></smiles>

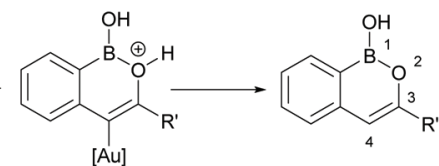

This work Wacker-type oxidation [O]

(b)

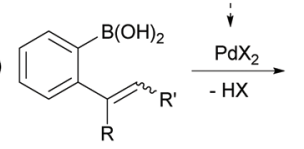<smiles>[CH]1CCCC1</smiles>

$\mathrm{OH}$

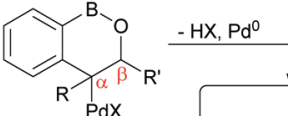
$\mathrm{PdX}$

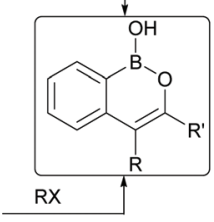

(c)

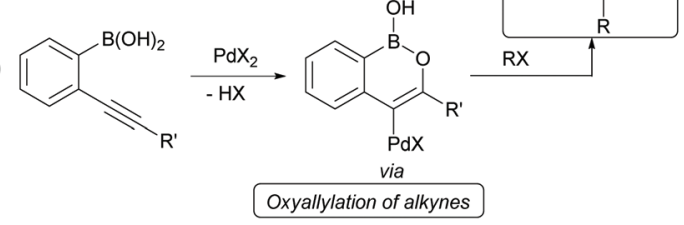

Scheme 1 Metal-catalysed approaches to benzooxaborinin-1-ols.

subsequently be trapped by an electrophile to afford a substituted benzooxaborin-1-ol.

To explore the proposed intramolecular oxidative cyclisation, we used commercially available 2-vinylbenzene boronic acid 1a as a test substrate. In the presence of a stoichiometric amount of $\mathrm{Pd}\left(\mathrm{CH}_{3} \mathrm{CN}\right)_{2} \mathrm{Cl}_{2}$, the boronic acid underwent cyclisation to afford the benzooxaborin-1-ol $\mathbf{2 a}$ as the sole product. Various sources of palladium(II) were also screened but none proved to be as efficient as $\operatorname{Pd}\left(\mathrm{CH}_{3} \mathrm{CN}_{2} \mathrm{Cl}_{2} \cdot{ }^{17}\right.$ We then sought to develop a catalytic method using an oxidant to regenerate the $\mathrm{Pd}(\mathrm{II})$ active species, and copper(II) chloride proved most effective. ${ }^{17}$ As often observed in Wacker-type oxidations, ${ }^{15}$ solvent appeared to be a crucial parameter. Typical polar solvents commonly used in $\operatorname{Pd}\left(\right.$ III)-catalysed oxidations, ${ }^{14}$ such as DMSO, acetonitrile and dioxane inhibited the reaction, even with stoichiometric quantities of $\mathrm{Pd}(\mathrm{II})$, presumably due to coordination to the metal centre which reduces the activity of the catalyst. However, the boronic acid 1a and copper(II) chloride are both highly insoluble in apolar solvents (PhMe, $\mathrm{CH}_{2} \mathrm{Cl}_{2}$, CPME) resulting in very low conversion and trimerisation of 1a to form the boroxine. Pleasingly, tert-butanol proved an effective solvent for the reaction, most likely by providing a balance between solubility of the reaction partners, reactivity and stabilisation of the metal centre. In the end the optimised parameters afforded 2a in $71 \%$ isolated yield (Scheme 2). An attempt to decrease the catalyst loading from 5 to $2 \mathrm{~mol} \%$ resulted in a significantly reduced yield (39\%). Finally, we also explored the use of catalytic amounts of palladium(II) and copper(II) chloride under aerobic conditions (1 atm. O2), which gave $2 \mathrm{a}$ in $30 \%$ yield.

With conditions in hand, we extended the reaction to other substrates (Scheme 3). We were pleased to find that $\mathbf{1 b}$ also underwent cyclisation. However the reaction produced a mixture of benzooxaborinin-1-ol $\mathbf{2 b}$ and 4-chloro-benzo-

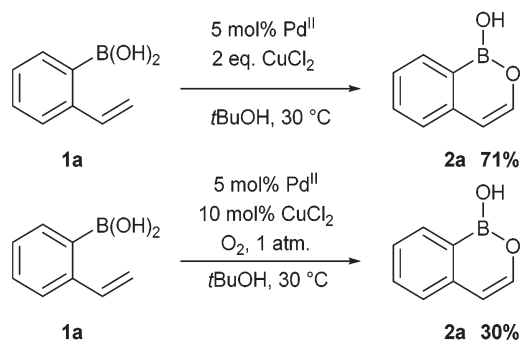

Scheme 2 Pd-catalysed cyclisation of 2-vinylbenzene boronic acid 1a.

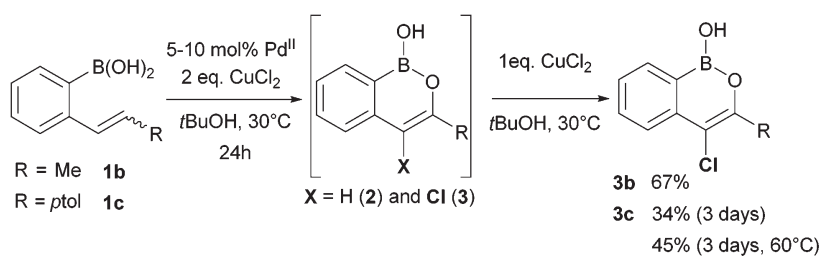

Scheme 3 Pd-catalysed cyclisation/chlorination of internal alkenes.

oxaborinin-1-ol $\mathbf{3 b}$ which were inseparable by chromatography. This issue was addressed by treatment of the mixture of $\mathbf{2} \mathbf{b} / \mathbf{3} \mathbf{b}$ with one equivalent of $\mathrm{CuCl}_{2}$ in tert-butanol to afford a pure sample of 4-chlorobenzooxaborininol $\mathbf{3 b}$ in moderate yield over the two steps (58\%). Arylsubstituted alkene 1c was less reactive, necessitating an increase in catalyst loading and a longer reaction time to afford the chloro-oxaborine $3 \mathrm{c}$ in $34 \%$ yield (Scheme 3), or $45 \%$ at $60{ }^{\circ} \mathrm{C}$.

In order to explore the direct synthesis of a 4-alkyl benzooxaborin-1-ol, we examined the cyclisation of boronic acid 1d (Scheme 4). This compound was also less reactive under the standard conditions, with a longer reaction time and a higher catalyst loading being required to observe full conversion of the starting material. Interestingly, the formation of the expected product $\mathbf{2 d}$ was not observed, with the major product arising from the reaction being the chloride $\mathbf{3 b}$ ( $67 \%$ isolated yield). In addition, traces of 1,1-dimethylbenzooxaborole $4 d$ were observed. The formation of $\mathbf{3 b}$ could potentially be explained by cationic rearrangement of the possible reaction intermediate $\mathbf{5}$. The chlorinated benzooxaborinin-1-ols $\mathbf{3 b}-\mathbf{3 c}$

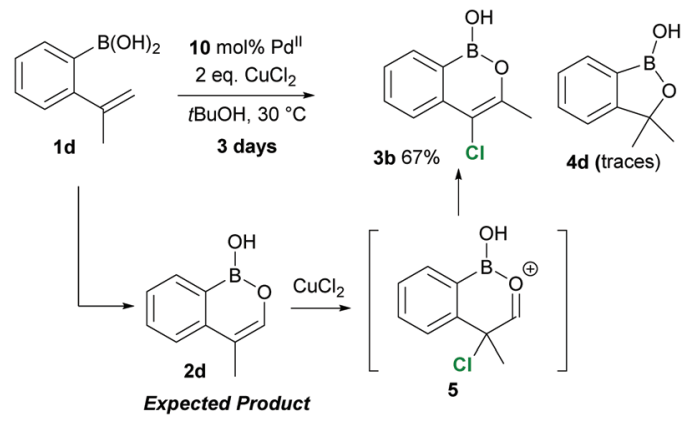

Scheme 4 Pd-catalysed cyclisation/chlorination of a 1,1-disubstituted alkene. 
are formally halogenated boron enolates, a class of compounds that has never previously been structurally characterised. ${ }^{18}$ Importantly, however, the presence of the chlorine atom at $\mathrm{C} 4$ increases the stability of the benzooxaborinin-1-ol ring system, and these compounds are air and moisture stable and can readily be isolated. We hypothesised that the copper(II) chloride co-oxidant was responsible for the chlorination of the ring, and to confirm this we examined direct halogenation of benzooxaborinin-1-ol 2e (Table 1, entry 1), prepared via gold-catalysed cyclisation of the corresponding $o$-alkynylbenzeneboronic acid. ${ }^{12}$ Pleasingly, the chlorinated compound $3 \mathrm{e}$ was obtained from $2 \mathrm{e}$ in good yield, upon treatment with copper(II) chloride (2 eq.) in $t$-BuOH; $N$-chlorosuccinimide (1 eq.) was also effective for this transformation (entry 2), though gave a lower yield. When copper(II) bromide was used, the brominated benzooxaborinin-1-ol (Br-3e) was obtained in $63 \%$ yield (entry 3 ).

The position of the chlorine atom in $3 \mathbf{e}$ was unambiguously determined by ${ }^{13} \mathrm{C}\left\{{ }^{1} \mathrm{H}\right\}$ NMR, where the signal corresponding to the $\mathrm{C} 4$ carbon $\left(\delta_{\mathrm{C}} 114.2 \mathrm{ppm}\right)$ showed a slight splitting due to the two chlorine isotopes $\left({ }^{35} \mathrm{Cl}\right.$ and $\left.{ }^{37} \mathrm{Cl}\right) .{ }^{19}$ Subsequently, the solid state structure was confirmed by singly crystal X-ray diffraction (Fig. 2). As previously reported for analogous boron-oxygen heterocycles the pseudo-naphthalene core is a

Table 1 Halogenation of oxaborines (2e)

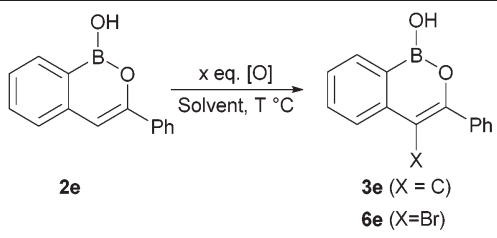

\begin{tabular}{llllll}
\hline Entry & Oxidant & Eq. $[\mathrm{O}]$ & Solvent & $T\left({ }^{\circ} \mathrm{C}\right)$ & Yields \\
\hline 1 & $\mathrm{CuCl}_{2}$ & 2 & $t$ BuOH & 30 & 82 \\
2 & $\mathrm{NCS}_{3}$ & 1 & $\mathrm{CH}_{3} \mathrm{CN}$ & R.T. & 61 \\
3 & $\mathrm{CuBr}_{2}$ & 2 & $t \mathrm{BuOH}$ & 30 & 63
\end{tabular}

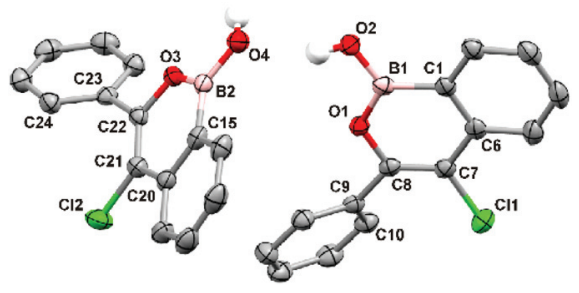

Fig. 2 X-ray crystal structure of the asymmetric unit of 4-chlorobenzooxaborin-1-ol 3e. Ellipsoids are shown at the 50\% probability level. Only the hydrogen atom bonded to $\mathrm{O} 2$ and $\mathrm{O} 4$ are shown for clarity. Selected interatomic distances $(\AA \AA)$ and bond angles ( $\left.{ }^{\circ}\right)$ : C6-C7 1.4613(19); C7-C8 1.3492(19); C8-O1 1.3786(16); O1-B1 1.3802(17); B1-O2 1.3642(19); C1-B1 1.529(2); C7-Cl1 1.7378(13); C7-C8-C9 129.55(12); C20-C21 1.4580(19); C21-C22 1.3473(19); C22-O3 1.3729(15); O3-B2 1.3791(18); B2-O4 1.3615(18); C15-B1 1.533(2); C21-Cl2 1.7454(13); C21-C22-C23 128.96(12). planar framework with a small degree of delocalization between the two rings. ${ }^{7 a}$ The terminal B-O bond (1.3642(19) and 1.3615(18)) appears slightly shorter than the endocyclic B-O bond (1.3802(17) and 1.3791(18)), but both are similar to the $\mathrm{B}-\mathrm{O}$ bond in a boronic acid. ${ }^{20}$ The phenyl ring at $\mathrm{C}-3$ is clearly tilted away from the heterocyclic plane suggesting little conjugation between these two fragments (torsion angle C7-C8-C9-C10 and C21-C22-C23-C24 of $45^{\circ}$ and $49^{\circ}$, respectively). Such distortion could be due to steric repulsion between the phenyl ring and the chlorine atom.

We envisioned that the benzooxaborole by-product $4 d$, obtained during the Pd-mediated cyclisation of 1d, was probably formed due to the hydrochloric acid released during the Wacker type oxidation process (Scheme 1), which could catalyse a formal intramolecular hydration of the alkene. Indeed, when substrate 1d was stirred in the presence of Amberlyst 15, the heterocyclic compound 4d was obtained in 55\% yield (Table 2, entry 1). By using a stoichiometric amount of $\mathrm{HCl}$ (generated from addition of $\mathrm{Me}_{3} \mathrm{SiCl}$ ) only a low conversion to compound 1d was seen after 24 hours (entry 2). Arylalkene 1c did not cyclise with a Brønsted acid (entry 3), but in the presence of catalytic platinium(Iv) chloride, both 1c and 1d were converted into the corresponding benzooxaboroles (entries 5 and 6).

As the Wacker-type oxidation procedure did not allow us to access benzooxaborininols bearing a carbon substituent at $\mathrm{C} 4$, we wished to explore alternative strategies. With this in mind, we were inspired by a recently reported cyclisation/allylation of alkenyl alcohols by palladium-catalysed reaction with allyl chlorides. ${ }^{21}$ We therefore sought to apply this reaction to the allylative cyclisation of $o$-alkynylbenzeneboronic acids (Table 3). Once again, tert-butanol proved to be the solvent of choice for this transformation, with more polar solvents inhibiting the reaction. The best conversion was obtained using $5 \mathrm{~mol} \%$ of $\mathrm{Pd}(\mathrm{PhCN})_{2} \mathrm{Cl}_{2}$ as catalyst at $30{ }^{\circ} \mathrm{C}$, and the presence of a mild base $\left(\mathrm{NaHCO}_{3}\right)$ and 5 equivalents of allyl chloride $7 \mathbf{a}$ were required to avoid competing proto-demetallation to give the unsubstituted benzooxaborininol. Under these conditions, aromatic substituents on the alkyne were well tolerated and

Table 2 Acid-catalysed formation of benzoboroles $4 c$ and $4 d$

\begin{tabular}{|c|c|c|c|c|c|}
\hline & & $w_{\mathrm{R}^{2}}^{\mathrm{H}_{2}} \frac{\text { Acid }}{\mathrm{tBuOH},}$ & & $\mathrm{OH}$ & \\
\hline Entry & Method & Substrate & $\mathrm{R}_{1}$ & $\mathrm{R}_{2}$ & Yield (\%) \\
\hline 1 & $\mathrm{~A}^{a}$ & 1d & $\mathrm{Me}$ & $\mathrm{H}$ & 55 \\
\hline 2 & $\mathrm{~B}^{b}$ & $1 d$ & $\mathrm{Me}$ & $\mathrm{H}$ & $10^{c}$ \\
\hline 3 & A & $1 c$ & $\mathrm{H}$ & $p$ Tol & 0 \\
\hline 4 & $\mathrm{C}^{d}$ & 1d & $\mathrm{Me}$ & $\mathrm{H}$ & 51 \\
\hline 5 & $\mathrm{C}$ & $1 \mathrm{c}$ & $\mathrm{H}$ & $p$ Tol & $24^{e}$ \\
\hline
\end{tabular}


Table 3 Palladium catalysed preparation of 4-allylbenzooxaborinin-1ols

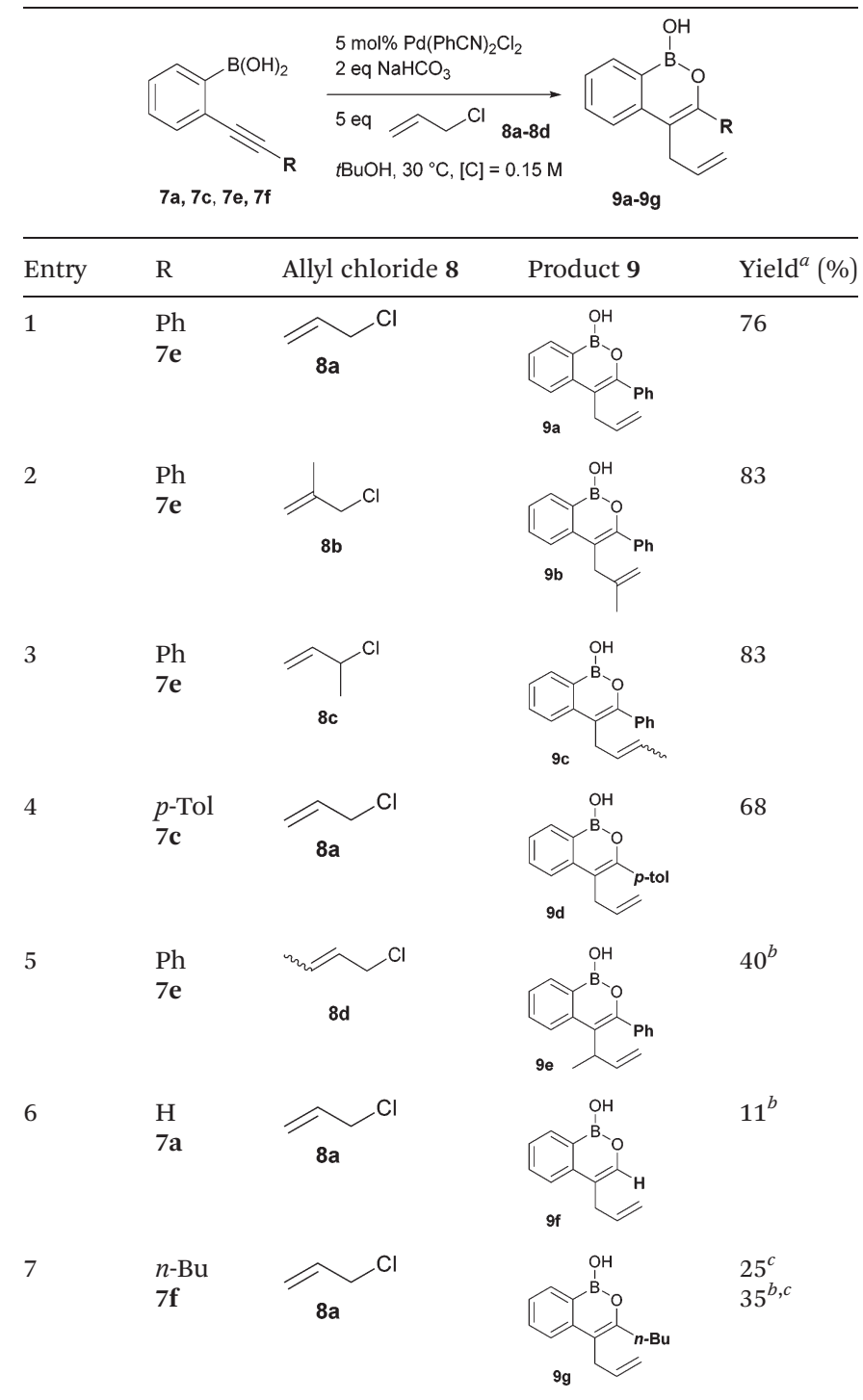

${ }^{a}$ Isolated yield. ${ }^{b} 50{ }^{\circ} \mathrm{C} .{ }^{c}$ Yield determined by ${ }^{1} \mathrm{H}$ NMR.

the 4-allylbenzooxaborininols $\mathbf{9 a - 9 e}$ were prepared in moderate to good yields (entries 1-5). Several allyl chlorides were then screened to determine the scope of the reaction with regard to the C-4 substituent. We were pleased to see that terminal allyl chlorides 8a-8c (entries 1-3) were excellent coupling partners for this transformation. In comparison, internal allyl chloride $8 \mathbf{d}$ required higher temperature $\left(50^{\circ} \mathrm{C}\right)$ to give a modest yield. Importantly, however, the use of the branched allyl chloride $\mathbf{8 c}$ gave the linear product $\mathbf{9 c}$, whereas linear allyl chloride 8d led to the exclusive formation of the branched product 9e. Whilst arylsubstituted alkynes worked well in the reaction, terminal and alkyl-substituted alkynes were somewhat prone to competitive proto-demetallation which resulted in an inseparable mixture of allylated product and the corresponding 4-H benzooxaborininol (entries 6 and 7).
In conclusion, we have developed new palladium-catalysed reactions for the preparation of 4-substituted-benzooxaborinols. The transformations occur under mild conditions using tert-butanol as solvent, which was crucial for enabling effective catalytic turnover of the palladium whilst maintaining sufficient catalyst reactivity. Firstly, a Wacker type oxidation of $o$-alkenylbenzeneboronic acids allowed the preparation of previously unreported 4-chlorobenzooxaborininols, which could also be accessed by direct halogenation of the parent 4-H benzooxaborininols. In parallel, careful analysis of the by-products generated during this reaction led to the discovery of a new route to benzooxaboroles. We have also developed a palladium catalyzed cyclisation/allylation of alkynylbenzene boronic acids to afford 4-allyl-benzooxaborininols. Thus, the two synthetic routes provide complementary approaches to different classes of 4-substituted benzooxaborininols. Finally, our study has successfully demonstrated that addition of a substituent at C-4 of this unusual boron/oxygen heterocycle greatly increases the stability of the compounds, making them a potentially attractive new heterocyclic ring system for use in medicinal chemistry.

We would like to thank the Engineering and Physical Sciences Research Council (Grant reference EP/K001183/1) for supporting this work. We would also like to acknowledge the EPSRC National Mass Spectrometry Facility at Swansea University for providing analytical services.

\section{Notes and references}

1 D. G. Hall, Boronic Acids. Preparation and Applications in Organic Synthesis and Medicine, Wiley, Weinheim, 2005.

2 (a) K. Ishihara, S. Ohara and H. Yamamoto, J. Org. Chem., 1996, 61, 4196; (b) R. M. Al-Zoubi, O. Marion and D. G. Hall, Angew. Chem., Int. Ed., 2008, 47, 2876; (c) R. M. Lanigan, P. Starkov and T. D. Sheppard, J. Org. Chem., 2013, 78, 4512; (d) S. Liu, Y. Yang, X. Liu, F. K. Ferdousi, A. S. Batsanov and A. Whiting, Eur. J. Org. Chem., 2013, 5692; $(e)$ T. M. El Dine, J. Rouden and J. Blanchet, Chem. Commun., 2015, 51, 16084.

3 (a) O. Conrad, C. Jansen and B. Krebs, Angew. Chem., Int. Ed., 1998, 37, 3208; (b) S. Yamaguchi and A. Wakamiya, Pure Appl. Chem., 2006, 78, 1413; (c) A. Lorbach, A. Hübner and M. Wagner, Dalton Trans., 2012, 41, 6048; (d) D. Frath, J. Massue, G. Ulrich and R. Ziessel, Angew. Chem., Int. Ed., 2014, 53, 2290.

4 For a review, see: T. Kowada, H. Maeda and K. Kikuchi, Chem. Soc. Rev., 2015, 44, 4953.

5 (a) S. J. Baker, C. Z. Ding, T. Akama, Y.-K. Zhang, V. Hernandez and Y. Xia, Future Med. Chem., 2009, 1, 1275; (b) B. C. Das, P. Thapa, R. Karki, C. Schinke, S. Das, S. Kambhampati, S. K. Banerjee, P. Van Veldhuizen, A. Verma, L. M. Weiss and T. Evans, Future Med. Chem., 2013, 5, 653; (c) J. Kahlert, C. J. D. Austin, M. Kassiou and L. M. Rendina, Aust. J. Chem., 2013, 66, 1118. 
6 (a) F. Issa, M. Kassiou and L. M. Rendina, Chem. Rev., 2011, 111, 5701; (b) R. Smoum, A. Rubinstein, V. M. Dembitsky and M. Srebnik, Chem. Rev., 2012, 112, 4156; (c) R. L. Moss, Appl. Radiat. Isot., 2014, 88, 2.

7 (a) J. Chen, Z. Bajko, J. W. Kampf and A. J. Ashe, Organometallics, 2007, 26, 1563; (b) J. F. Araneda, W. E. Piers, M. J. Sgro and M. Parvez, Organometallics, 2015, 34, 3408; (c) M. J. D. Bosdet, W. E. Piers, T. S. Sorensen and M. Parvez, Angew. Chem., Int. Ed., 2007, 46, 4940; (d) J. F. Araneda, W. E. Piers, B. Heyne, M. Parvez and R. McDonald, Angew. Chem., Int. Ed., 2011, 50, 12214; (e) L. Liu, A. J. V. Marwitz, B. W. Matthews and S.-Y. Liu, Angew. Chem., Int. Ed., 2009, 48, 6817; $(f)$ P. G. Campbell, A. J. V. Marwitz and S.-Y. Liu, Angew. Chem., Int. Ed., 2012, 51, 6074; $(g)$ X. Liu, Y. Zhang, B. Li, L. N. Zakharov, M. Vasiliu, D. A. Dixon and S.-Y. Liu, Angew. Chem., Int. Ed., 2016, 55, 8333; (h) A. N. Brown, B. Li and S.-Y. Liu, J. Am. Chem. Soc., 2015, 137, 8932.

8 (a) X. Li, J. J. Plattner, V. Hernandez, C. Z. Ding, W. Wu and Y. Yang, Tetrahedron Lett., 2011, 52, 4924; (b) C. T. Liu, J. W. Tomsho and S. J. Benkovic, Bioorg. Med. Chem., 2014, 22, 4462; (c) A. Adamczyk-Wozniak, K. M. Borys and A. Sporzynski, Chem. Rev., 2015, 115, 5224.

9 (a) M. J. S. Dewar and R. Dietz, Tetrahedron Lett., 1959, 14, 21; (b) M. J. S. Dewar and R. Dietz, J. Chem. Soc., 1960, 1344; (c) For an unusually stable 1,3,2-dioxaborinin-2-ol, see: M. N. Pennell, M. P. Kyle, S. M. Gibson, L. Male, P. G. Turner, R. S. Grainger and T. D. Sheppard, Adv. Synth. Catal., 2016, 358, 1519.

10 (a) W. Maringgele, A. Meller, M. Noltemeyer and G. M. Sheldrick, Z. Anorg. Allg. Chem., 1986, 536, 24; (b) L. M. Greig, A. M. Z. Slawin, M. H. Smith and D. Philp,
Tetrahedron, 2007, 63, 2391; (c) D. Carnevale, V. Del Amo, D. Philp and S. E. Ashbrook, Tetrahedron, 2010, 66, 6238; (d) Y. Sumida, R. Harada, T. Kato-Sumida, K. Johmoto, H. Uekusa and T. Hosoya, Org. Lett., 2014, 16, 6240.

11 S. M. Mathew and C. S. Hartley, Macromolecules, 2011, 44, 8425 .

12 C. Körner, P. Starkov and T. D. Sheppard, J. Am. Chem. Soc., 2010, 132, 5968.

13 R. Guo, K.-N. Li, B. Liu, H.-J. Zhu, Y.-M. Fan and L.-Z. Gong, Chem. Commun., 2014, 50, 5451.

14 For bromolactonisations of unsaturated boronic acids, see: J. R. Falck, M. Bondlela, S. K. Venkataraman and D. Srinivas, J. Org. Chem., 2001, 66, 7148.

15 For reviews on Pd-catalysed oxidation of alkenes, see: (a) R. I. Mcdonald, G. Liu and S. S. Stahl, Chem. Rev., 2011, 111, 2981; (b) S. E. Mann, L. Benhamou and T. D. Sheppard, Synthesis, 2015, 3079.

16 (a) Y. Wakabayashi, Y. Fukuda, H. Shiragami, K. Utimoto and H. Nozaki, Tetrahedron, 1985, 41, 3655; (b) Y. Fukuda, H. Shiragami, K. Utimoto and H. Nozaki, J. Org. Chem., 1991, 56, 5816; (c) C. Martínez, R. Álvarez and M. Aurrecoechea, Org. Lett., 2009, 11, 1083.

17 Please see ESI† for further details.

18 G. F. Hambly and T. H. Chan, Tetrahedron Lett., 1986, 27, 2563.

19 The isotope shift observed is approximately $5 \mathrm{ppb}$ and is in agreement with data reported in the literature, see: A. E. Aliev and K. D. M. Harris, Magn. Reson. Chem., 1993, 31, 54 .

20 B-O bond length in $\mathrm{PhB}(\mathrm{OH})_{2}=1.371$ (7) $\AA$, see ref. $7 a$.

21 J. F. M. Hewitt, L. Williams, P. Aggarwal, C. D. Smith and D. J. France, Chem. Sci., 2013, 4, 3538. 